\title{
A New Approach and Tools for Perfecting Phytoremediation Technology
}

\author{
Tamar Varazi ${ }^{1}$, Maritsa Kurashvili ${ }^{1}$, Marina Pruidze ${ }^{1}$, Gia Khatisashvili ${ }^{1}$, Nino Gagelidze ${ }^{1}$, \\ George Adamia ${ }^{1}$, George Zaalishvili ${ }^{1}$, Marlen Gordeziani ${ }^{1}$, Mark Sutton ${ }^{2}$ \\ ${ }^{1}$ Durmisidze Institute of Biochemistry and Biotechnology of Agricultural University of Georgia, David Agmashenebli Alley 240, Tbilisi, \\ Georgia \\ ${ }^{2}$ Chemical Sciences Division, Lawrence Livermore National Laboratory, California, USA
}

\begin{abstract}
Email address:
t.varazi@agruni.edu.ge (T. Varazi), m.kurashvili@agruni.edu.ge (M. Kurashvili), m.pruidze@agruni.edu.ge (M. Pruidze), g.khatisashvili@agruni.edu.ge (G. Khatisashvili),n.gagelidze@agruni.edu.ge (N. Gagelidze), g.adamia@agruni.edu.ge (G. Adamia), g.zaalishvili@agruni.edu.ge (G. Zaalishvili),m.gordeziani@agruni.edu.ge (M. Gordeziani),sutton18@1lnl.gov (M. Sutton)
\end{abstract}

\section{To cite this article:}

Tamar Varazi, Maritsa Kurashvili, Marina Pruidze, GiaKhatisashvili, Nino Gagelidze, George Adamia, George Zaalishvili, MarlenGordeziani, Mark Sutton. A New Approach and Tools for Perfecting Phytoremediation Technology. American Journal of Environmental Protection. Special Issue: Applied Ecology: Problems, Innovations. Vol. 4, No. 3-1, 2015, pp. 143-147. doi: 10.11648/j.ajep.s.2015040301.32

\begin{abstract}
The development of methods for soil remediation for removal of chemical contaminants is a large and challenging problem. A new phytoremediation technology, given in the present work, is based on joint application of natural sorbents, microorganisms and plants. The method aims at prevention of chemical contamination of soils. It has the potential to restore a polluted environment and prevent dissemination of toxic compounds from hotbeds of pollution for a considerable length of time. The presented complex biotechnology is important from the viewpoint of prevention. This technology can be applied to soils contaminated with heavy metals, oil hydrocarbons, explosives, pesticides and other pollutants. The main purpose of the carried out work is the development of a novel approach to the provision of ecological safety. The approach is based on using natural minerals composites which are comprised of natural mineral rocks, microorganism strains with high detoxification abilities and plants-phytoremediators. In this composite material, the function of a sorbent is to uptake and to trap pollutants thus restraining their emission in the environment. The role of the microorganisms is to accomplish the first stage of biodegradation of organic contaminants and then to apply phytoremediation as a unique cleanup strategy. Natural sorbent can be applied during the initial stage of cleaning up of contaminated soil, followed by application of a phytoremediation technology through purposeful planting of selected plants. This results in the total assimilation and complete mineralization of pollutants and/or their intermediates or in their partial transformation by microbes.Following contaminants were used in the present work: explosive - 2,4,6 trinitrotoluene (TNT), oil hydrocarbon (hexadecane) and Wax (long chain hydrocarbons). Special attention was paid to enhancement of soil fertility, which improves microorganism and plant growth conditions and is important for bioremediation processes providing total rehabilitation of soil.
\end{abstract}

Keywords: Phytoremediation, Bioremediation, Contaminated Soils

\section{Introduction}

Cleansing of polluted environment, its absolute restoration and long-term protection can be achieved effectively and cheaply via application of phytoremediation technologies [1]. In this case the ecological balance is maintained: molecules of chemical toxicants are totally assimilated by plants and the atoms, forming toxic structure of xenobiotics participating in the natural metabolism as harmless compounds.
Phytoremediation is a unique cleanup strategy. Application of phytoremediation technologies implies the planting of contaminated area with one or more specific, previously selected species of plants having the potential to extract contaminants from the soil [2-7]. The treatment continues by harvesting the plants and composting or incinerating them. To create a truly effective phytoremediation system all components of the system should be thoroughly analyzed. The major constitutive component of such a system is obviously the plant. Plant 
selection implies choosing a certain plant species with appropriate characteristics. A survey of the site vegetation should be undertaken in order to determine the species of plants that will grow best on the contaminated site, taking into account the ability of the plants to accumulate and degrade the contaminants.

Phytoremediation has great advantage over other nonbiological and biological technologies. It is envisaged by many private or state companies while projecting and accomplishing remediation or prevention activities.

Some limitations to phytoremediation should be pointed out - very high concentration of pollutants, e.g. accidental oil spills, may significantly reduce plant growth. Therefore, dissemination of toxic compounds from the hotbeds of pollution in the environment (e.g. groundwater) occurs at a higher pace than in case plants provide their assimilation.

The main purpose of the carried out work, is to reduce limitations to phytoremediation, and to develop a new technological approach to the remediation of chemically contaminated soils using "biosorbents" - composites of natural mineral sorbents and microorganism strains with high detoxification abilities. In this composite material, the function of a sorbent is to uptake and to trap pollutants, thus restraining their emission in the environment. The role of the microorganisms is to accomplish the first stage of biodegradation of organic contaminants and then to apply phytoremediation as a unique cleanup strategy. Natural sorbent can be applied during the initial stage of cleaning up of contaminated soil, followed by application of a phitoremediation technology through purposeful planting of selected plants. This results in the total assimilation and complete mineralization of pollutants and/or their intermediates or in their partial transformation by microbes.

By combining specially selected microorganisms having high detoxification abilities with natural minerals having high sorption capacities, a new "biosorbent" technology provides restoration of the polluted environment, and prevents the dissemination of toxic compounds from hotspots of pollution for a considerable period of time. The method can be used to purify and decontaminate soils and water contaminated by a variety of eco-pollutants, including heavy metals, radionuclides, alkanes, aromatic and polycyclic hydrocarbons, pesticides, explosives, chlorinated solvents etc.

The purpose of the present project is to elaborate a new technological approach to chemically contaminated soils, based on simultaneous application of sorption properties of natural minerals and detoxificational abilities of microorganisms and plants.

\section{Materials and Methods}

\subsection{Screening of Bacterial Strains}

Bacterial cultures from the Collection of Microorganisms of Durmishidze Institute of Biochemistry and Biotechnology of the Georgian Agricultural University were used to determine the strains capable of degrading different organic pollutants, particularly crude oil, wax and 2,4,6-trinitrotoluene (TNT).

\subsection{Plants}

The following plant species were tested as vegetation to be used in purposeful planting during our investigation: maize (Zea mays), alfalfa (Medicagosativa), mung bean (Vignaradiata), ryegrass (Loliummultiflorum), soybean (Glycinemax), chickling vetch (Lathyrussativum), chickpea (Cicerarietinum) and chinabean (Vignasinensis).

\subsection{Investigation of Sorbents}

Standard methods were applied to define physical-chemical features (volumetric weight, porosity, displacement, filtration characteristics, oil absorption potential, absorption dependence on temperature, $\mathrm{pH}$, etc.) of rocks [8].

\subsection{TPH Determination}

The sampling of soil was carried out according to standard methods. The content of total petroleum hydrocarbons (TPH) in the soil samples was measured gravimetrically after Soxhlet extraction as well as by gas chromatography with flame ionization (FID) detection [10-12].

\subsection{TNT Determination}

TNT content in the samples was determined according to the extinction of colorized TNT in high alkaline medium $(\mathrm{pH}>12.2)$ at $447 \mathrm{~nm}$ [9].

For determination of residual amounts of TNT, a sample of soil was taken and TNT was extracted by methanol (three times with $300 \mathrm{ml}$ of ethanol on $50 \mathrm{~g}$ air-dried soil, mixed during 30 minutes). Extracts were concentrated to a volume of $5 \mathrm{ml}$ on the vacuum-evaporator, then $2 \mathrm{ml}$ of this extract was added to $2 \mathrm{ml}$ of $\mathrm{KOH}$ solution $(1 \mathrm{M})$ and after 8 minutes TNT content was determined spectrophotometrically, according to extinction at $447 \mathrm{~nm}$. The amount of TNT determined at the beginning of the experiment was used as the control.

In case of experiments with $\left[1-{ }^{14} \mathrm{C}\right] \mathrm{TNT}$, the air-dried soil was weighed (mass of sample $7 \mathrm{~kg}$ ), $0.5 \mathrm{~L}$ of solution of $1.05 \mathrm{~g}$ $\left[1-{ }^{14} \mathrm{C}\right] \mathrm{TNT}$ (specific radioactivity $500 \mathrm{~Bq} / \mathrm{mg}$ ) in diethyl ether was added and was thoroughly mixed. The ether was evaporated during 2 days. After that $10 \%$ suspension of microorganisms was added to the samples and was dried to up to $130 \%$ of initial weight (according to the standards of soil investigations). Thereafter the soil was placed in special boxes for the experiments and the soybean seeds were sowed in samples (80 seeds on $7 \mathrm{~kg}$ of soil).

For determination of radioactivity of soil samples the methanol extract was evaporated until dry residue. The dry residue was dissolved in $5 \mathrm{ml}$ of benzene; $1 \mathrm{ml}$ sample was taken and was measured with the scintillation spectrometer SL-30 Rackbeta, with an efficiency of 95\%.

Thin-layer chromatographic (TLC) analysis of methanol extracts from polluted soil samples was carried out. The plates were developed with mixture: benzene: dioxane : acetic acid (90:10:1). The chromatograms were exposed on X-ray film 
during 45 days for revelation of radioactive spots. After exposition the radioactive spots were extracted from chromatograms with benzene and their radioactivities were measured.

\section{Results and Discussions}

\subsection{Sorbents}

Application of mineral composites is important in case of all types of contamination, as, on the one hand, it is significant from the viewpoint of prevention, and, on the other hand, it creates favorable conditions for growth of vegetation. After the introduction of the composites into the upper part of the soil and as a result of subsequent watering, the composites become swollen and stimulate growth and development of vegetation at the corresponding stage of phytoremediation.

Three types of mineral rocks were studied for the potential to be used as biosorbent - 2 types of Bentonites and Zeolite. The absorption ability of minerals and their composites for oil and TNT were studied. In composite ratio of minerals for each contaminant was different. Composite content against contaminants was the following: for TNT $-\mathrm{B} 1 / \mathrm{Z} 3$ in ratio $1 / 3$, for oil $-\mathrm{B} 1 / \mathrm{Z} 3$ in ratio $2 / 3$. It has been stated, content of composites in soil $-20 \%$.

\subsection{Soil Contaminated with Crude Oil and Wax}

\subsubsection{Selection of Microorganisms}

Screening of 200 strains of microorganisms was performed to study their abilities to effectively assimilate oil hydrocarbons during growth on media containing crude oil. As a result, optimal growth conditions (content of nutrient medium, $\mathrm{pH}$, temperature) were established, resulting in 20 selected strains. The ability of these selected strains to degrade oil hydrocarbons was determined by their submerged cultivation in nutrient media with crude oil $(3 \%)$ as the sole carbon source.

The gas-chromatographic analysis has shown that Pseudomonas and Rhodococcus strains were the most efficient combination of bacterial cultures for oil degradation. Chromatographic analysis also revealed that hydrocarbon fractions up to $\mathrm{C}_{17}$ are assimilated completely, while a small amount of heavier hydrocarbons $\left(>C_{17}\right)$ remain in the incubation medium.

\subsubsection{Plants}

The following plant species: alfalfa (Medicago sativa), chickpea (Cicerarietinum), chickling vetch (Lathyrussativum), maize (Zea mays), pea (Pisumsativum), ryegrass (Loliummultiflorum), and soybean (Glycine max) were used as phytoremediators.

The model phytoremediation experiments for cleaning the soil artificially contaminated with crude oil were carried out according to the following scheme: the suspension of microorganisms was inoculated in the contaminated soil at the beginning of the experiment. After different incubation periods the plants were sowed in separate samples of soil. The conditions and details of experiments are presented in legends of Fig. 1.

As shown in Fig.1, bacterial consortia cause effective decreasing of oil content in soil in all model test variants (43-74\% of initial contamination). Residual contamination of soil removes after plant using in phytoremediation processes. (55-90\% of initial contamination). Most effective phytoremediator in presenting experiment is soybean.

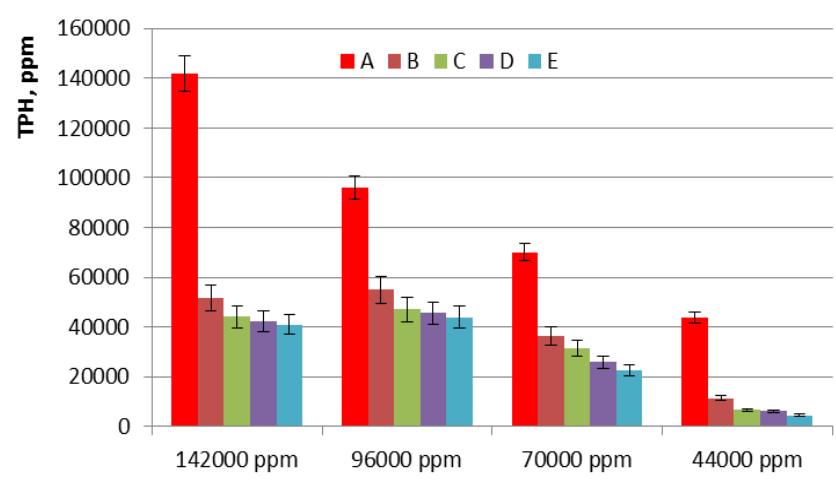

Figure 1. TPH content in soils contaminated with oil hydrocarbons after being treated by bacterial consortium (Rhodococcus sp. MO227 and Pseudomonas sp. TP 335) and sowing of plants. The suspension of bacteria was inoculated in the soil at the beginning of the experiment. On $31^{\text {th }}$ day of incubation the plants were sowed in separate samples of soil. Initial degree of contamination: 142 000; $96000 ; 70000$ and 44000 ppm of TPH; total time of incubation: 2 months; temperature: $20-2{ }^{\circ} \mathrm{C}$. Sample variants: $A-$ Contaminated soil in the beginning of the experiment. B - Soil treated by bacterial consortium. $C$ - Soil treated by bacterial consortium and sowed with ryegrass. $D$ - Soil treated by bacterial consortium and sowed with alfalfa. E-Soil treated by bacterial consortium and sowed with soybean.

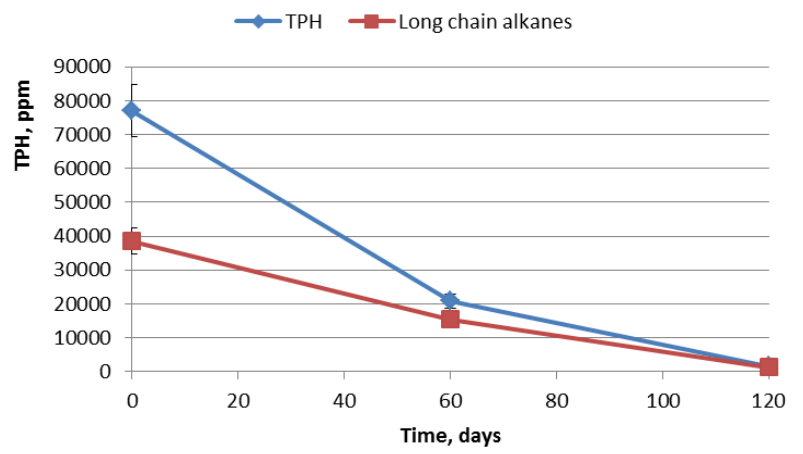

Figure 2. Phytoremediation of soil artificially contaminated with crude oil and wax by using of Alfalfa, bacterial consortium (Pseudomonas sp. 6R67+ Bacillus spp.). Initial contamination of soil with TPH - 77000 ppm, duration of experiment -4 months.

\subsection{Soil Contaminated with TNT}

\subsubsection{Selection of Microorganisms}

The screening of microorganisms for their ability to degrade TNT was performed. More than 200 bacterial strains from the Durmishidze Institute of Biochemistry and Biotechnology Collection of Microorganisms and Cultures were tested. These strains were isolated from the soils of different regions of Georgia, including the soil of proving grounds in the territory of Georgia.

The screening was carried out in the solid nutrient media containing different concentrations of TNT $(0.01 \mathrm{mM}, 0.1$ 
$\mathrm{mM}$ and $1.0 \mathrm{mM}$ ) as the source of carbon and nitrogen. As a result of the screening 34 strains of genera of Pseudomonas, 1 strain of Bacillus, 8 strains of Rhodococcus and 5 strains of Mycobacterium were proven to be characterized by good growth on the solid nutrient medium containing $1 \mathrm{~m}$ MTNT, and were subsequently selected. For these strains optimal growth conditions (content of nutrient medium, $\mathrm{pH}$, temperature) were established. In order to increase efficiency of selected strains towards TNT degradation, 7 different bacterial combinations were composed and tested under conditions of submerged cultivation containing $0.5 \mathrm{M}$ of TNT. The cultivation was conducted during 3-7 days on a thermostatic shaker (180-200 rev. per min; at a temperature of $28-30^{\circ} \mathrm{C}$ ) in a modified Czapek agar, containing $0.5 \mathrm{mM}$ TNT. Glucose was added to the activation of strains.

\subsubsection{Plants}

High tolerance of soybean to TNT while comparing the growth parameters of testing plants should be mentioned. Growth parameters of this plant on the saturated solution of explosive $(1.0 \mathrm{mM})$ decrease only by $5-10 \%$. To summarize the data, it can be concluded that the tolerance of tested 8 plants to TNT decreases according to following orders:

\section{Soybean $>$ Mung bean $>$ Ryegrass $>$ Chickpea $>$ Chickling vetch $>$ Alfalfa $>$ China bean $>$ Maize}

\subsubsection{Model Experiments}

For the purpose testing of selected consortia and plants, was carried out model experiments by using $\left[1-{ }^{14} \mathrm{C}\right] \mathrm{TNT}$ contaminated soils (conditions of the experiment are given in 2.5). The obtained results are present in Fig.3 and Fig.4.

According to the obtained results, presented inFig. 3, content of TNT in soil decrease, but radioactivity remaining in the soil. Results of TLC analyze indicates formation of TNT radioactive metabolites in soil (Fig. 4). After a short period of bioremediation (after 8 days) was accomplished purposeful planting of soils. The radioactive metabolites, formed as a result of bacterial transformation of $\left[1-{ }^{14} \mathrm{C}\right] \mathrm{TNT}$, were effectively uptake from the soil by the plants. Fig. 4 evidences dynamic decrease of radioactivity and amount of metabolites with different $\mathrm{R}_{\mathrm{f}}$ in soil extracts.

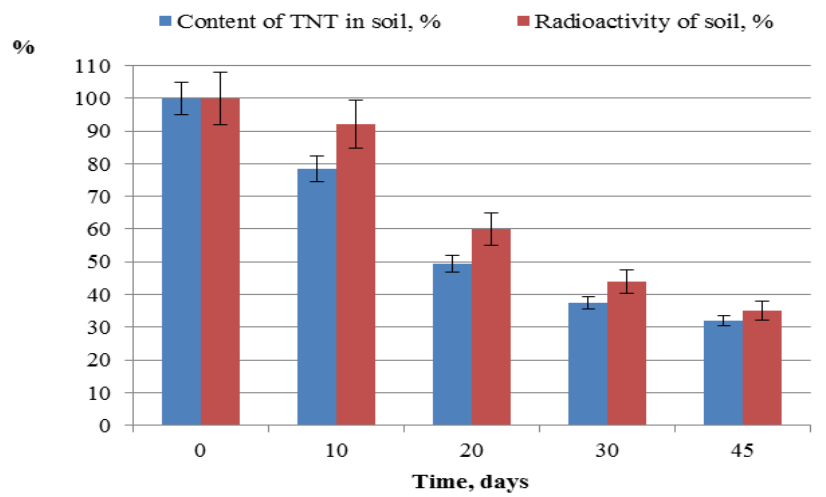

Figure 3. The dynamics of changing of TNT content in soil contaminated with $\left[1-{ }^{14} \mathrm{C}\right] \mathrm{TNT}$ during cleaning by soybean and bacterial consortium containing strains of Pseudomonas sp. TNT-44 and Rhodococcus sp. TNT-74.

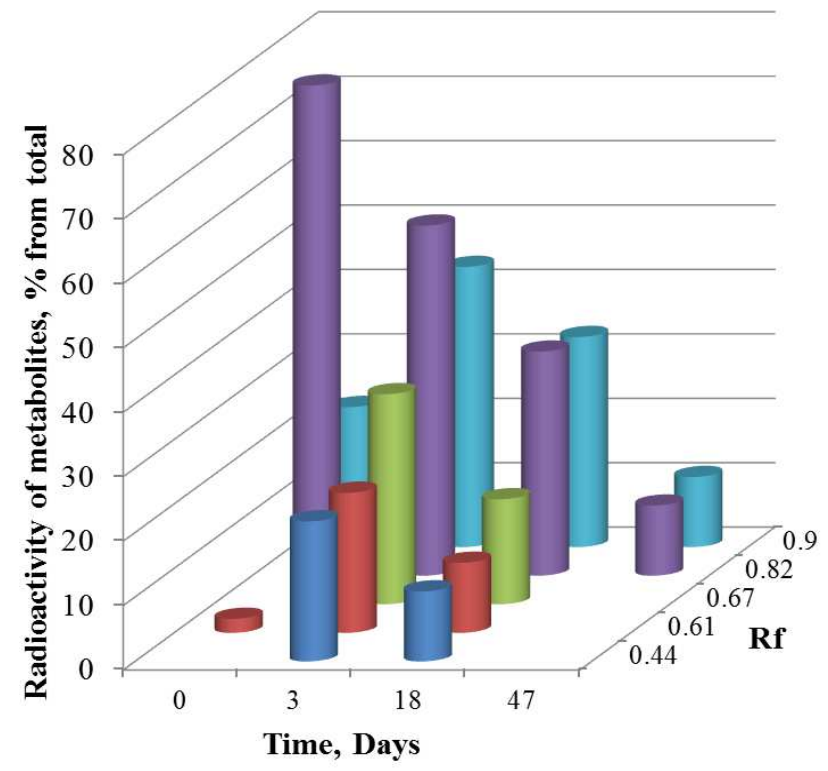

Figure 4. TLC analyses of $\left[1-{ }^{14} \mathrm{C}\right]$ TNT metabolites extracted from samples of polluted soil on $3^{\text {rd }}, 18^{\text {th }}$ and $47^{\text {th }}$ days of the remediation process

\section{Conclusion}

1. It has been stated, content of composites for each contaminants: For TNT $-\mathrm{B} 1 / \mathrm{Z} 3$ in ratio $1 / 3$, For oil $\mathrm{B} 1 / \mathrm{Z3}$ in ratio $2 / 3$.

2. According to carried out model experiments was stated:

- For effective phytoremediation of crude oil contaminated soil, can be used bacterial consortia Rhodococcus sp. MO227 and Pseudomonas sp. TP 335 and Soybean.

- For effective phytoremediation of wax contaminated soil, can be used bacterial consortia Pseudomonas sp. 6 R67 + Bacillus spp. and Alfalfa.

- For effective phytoremediation of TNT contaminated soil, can be used bacterial consortia Pseudomonas sp. TNT-44 and Rhodococcus sp. TNT-74 and Soybean.

\section{Acknowledgements}

This work was supported by STCU Partner Project \# P499. In addition, Lawrence Livermore National Laboratory is operated by Lawrence Livermore National Security, LLC, for the U.S. Department of Energy, National Nuclear Security Administration under Contract DE-AC52-07NA27344.

\section{References}

[1] F. Korte, M. Behadir, W. Klein, J.P. Lay, H. Parlar, and I. Scheunert, "Lehrbuch der okologischen chemie," Grundlagen and Konzepte fur die Okologische Beureilung von Chemikalien.Suttgart, Georg Thieme Verlag, 1992.

[2] E.L. Arthur, and J.R. Coats, "Phytoremediation," In: Pesticide Remediation in Soils and Water, P. Kearney and T. Roberts. Eds. New York, Wiley, 1998. 
[3] D.E. Salt, M. Blaylock, P.B.A. Nanda Kumar, V.P.Dushenkov, B.D. Ensley, I. Chet, and I. Raskin, "Phytoremediation: a novel strategy for the environment using plants," Biotechnology, vol. 13, 1998, pp. 468-474.

[4] D.T.Tsao, "Phytoremediation. Advances in Biochemical Engineering and Biotechnology," Berlin Heidelberg New York, Springer, 2003.

[5] G. Kvesitadze, G. Khatisashvili, T. Sadunishvili, and J.J.Ramsden, "Biochemical Mechanisms of Detoxification in Higher Plants," Basis of Phytoremediation, Berlin Heidelberg New York, Springer, 2006.

[6] AS 482.2 Guide to the sampling and investigation of potentially contaminated soils, 1999 .

[7] Dee Schnoor, "Phytoremediation," Technology Evaluation
Report TE-98-01, Ground-Water Remediation Technologies Analysis Center, Ser E. Iowa City, 1997.

[8] G.S.Fomin, and A.G.Fomin, "Soil. Control of quantity and ecological safety according to international standards," Moscow, BNII Standard, 2001.

[9] NWTPH-HCID "Hydrocarbon Identification Method for Soil and Water", 2001.

[10] US EPA Method3540C "Soxhlet Extraction;” Method 8572A. "Semivolatile organic compounds in soils and solid wastes using thermal extraction/gas chromatography/mass spectrometry", 1996.

[11] US EPA Method 418.1. "Total petroleum hydrocarbons," 1997.

[12] TNRCC Method 1006. "Characterization of $\mathrm{C}_{6}-\mathrm{C}_{35}$ petroleum hydrocarbons in environmental samples," 2000. 